\title{
Segurança pública e desenvolvimento local: Experiências do Brasil, Colômbia e Japão
}

Decio Estevão do Nascimento decio@utfpr.edu.br

Universidade Tecnológica Federal do Paraná (UTFPR), Curitiba, Paraná, Brasil.

Marcos Aurélio Nascimento Teixeira

mant@utfpr.edu.br

Universidade Tecnológica Federal do

Paraná (UTFPR), Curitiba, Paraná, Brasil.

\section{RESUMO}

Uma sociedade para prosperar necessita sentir-se segura em todo o conceito do termo. Certamente, este entendimento passa pela preservação da segurança física e patrimonial. Objetivo deste artigo é relacionar segurança pública com aspectos do desenvolvimento local. A pesquisa pretende discutir uma nova visão de segurança pública que, em certo grau de influência, pode colaborar para o desenvolvimento econômico de uma localidade, de uma região ou até de um país. Em termos metodológicos, a pesquisa utiliza da técnica de pesquisa bibliográfica, com uma análise qualitativa do problema. Como principais resultados a pesquisa aponta para a necessidade da concepção de segurança pública apropriada a um Estado democrático, e que contemple as seguranças econômicas, sociais e culturais; utilizando o mínimo de força possível e o máximo de ampliação das oportunidades e direitos sociais.

PALAVRAS-CHAVE: Segurança Pública. Desenvolvimento Local. Polícia Comunitária. 


\section{INTRODUÇÃO}

O empreendedor para prosperar com a atividade que pretende desenvolver atenta, normalmente, para as quatro funções administrativas básicas, ou seja: planejar, organizar, dirigir e controlar. Mas além destas preocupações, o empreendedor brasileiro se depara com o medo e insegurança provocados, entre outros fatores, pela falta de segurança pública e ações públicas sólidas que lhe garanta pelo menos a preservação do seu patrimônio e até, em muitos casos, da própria vida. É neste cenário e com estes percalços que muitos empreendedores esbarram quando se lançam na epopéia de contribuir, com a geração de postos de trabalho e aumento da renda, para o desenvolvimento local. A insegurança pública não é o único fator condicionante para travar o desenvolvimento social e econômico de um lugar, mas contribui para que isto ocorra.

De acordo com Rocha (2005):

O aumento da violência urbana, em grande parte fruto de uma política econômica de exclusão social, tem em muito contribuído para a violação de direitos humanos e para o aumento da criminalidade em nossas cidades. Diante de uma população que se sente desprotegida, o Estado (União, Estados e Municípios) tem que oferecer uma resposta imediata, pois apesar das causas sociais, a criminalidade também tem seu caráter patológico, e deve ser combatida em qualquer situação social, esta é uma responsabilidade obrigatória do Estado para com a população.

Quando o Estado adotapolíticas públicaseficientes e decididas de modo eficaz, o cidadão, ao menos neste ponto, tem a sensação que mudanças estão se processando e que, com esforço pessoal associado a medidas econômicas corretas estabelecidas pela gestão governamental vigente, é possível reverter em parte a balança da miséria. Em condição de segurança, a mente pode fluir para a criatividade e para inovação, o que, no andar dos acontecimentos, gera avanço científico e tecnologia, bases consistentes para avanços socioeconômicos no contexto da globalização. De acordo com Santos (2012), "o mundo é um conjunto de possibilidades, cuja efetivação depende das oportunidades oferecidas pelos lugares". Neste sentido, segundo o autor, "o mundo escolhe alguns lugares e rejeita outros e, nesse movimento, modifica o conjunto dos lugares, o espaço como um todo" (SANTOS, 2012).

Conforme Sassen (2010), estudar o global acarreta um foco não apenas naquilo que é explicitamente global em escala, mas também em práticas e condições de escala local que são articuladas com a dinâmica global. Com o estudo em questão se pretende expor a fragilidade das políticas públicas em termos de segurança pública que são desenvolvidas no Brasil em comparação as políticas públicas adotadas em outros países, notadamente no Japão e Colômbia. Deste modo será gerada uma contribuição para estudos futuros sobre quais políticas públicas podem ser apropriadas para as condições econômicas e sociais do Brasil..

Neste contexto, o objetivo deste artigo é relacionar segurança pública com aspectos do desenvolvimento local. Em termos metodológicos, para se chegar ao objetivo geral, foi realizada uma pesquisa bibliográfica sobre os temas segurança 
pública no Brasil, o custo da segurança pública, as polícias comunitárias e exemplos exitosos de sua implementação.

\section{REFERENCIAL TEÓRICO}

Nesta seção serão apresentados e discutidos os temas segurança pública no Brasil, gastos com segurança pública no Brasil, polícia comunitária e exemplos nacional e internacionais de sua implementação.

\section{SEGURANÇA PÚBLICA NO BRASIL}

Necessita-se de uma concepção de segurança pública em nível nacional capaz de conjugar forças da sociedade, dentro de um Estado democrático, contemplando as seguranças econômicas, sociais e culturais para ampliação das oportunidades e da cidadania. O Estado tem a responsabilidade de assumir o processo de conter a violência e a criminalidade. A agenda política nacional merece críticas sobre a abordagem conferida ao debate sobre a segurança e defesa da cidadania, uma vez que a finalidade prioritária de todas as ações e políticas públicas nesta área devem estar focadas em assegurar a chamada "paz social”, conforme preceitua o art. 136 da Constituição Federal (BRASIL, 1988). Esta mesma Carta Magna estabelece que as instituições responsáveis pela segurança pública, em sentido estrito, são as polícias, no caso, a Polícia Federal, a Polícia Civil e a Polícia Militar dos Estados da Federação, além do Corpo de Bombeiros Militar e até as Guardas Municipais, mantidas pelos municípios com capacidade financeira para tal (BRASIL, 1988).

No Brasil, já há algum tempo, existe um debate sobre a necessidade de reformas de natureza institucional das polícias, sugerindo assim que o próprio modelo de polícia atualmente vigente é que estaria em crise (PINHEIRO, 1998). Fica claro que somente isto não é suficiente para fomentar segurança pública no país, pois estudos recentes indicam que o índice de elucidação dos crimes de homicídio é baixíssimo no Brasil. Estima-se, em pesquisas realizadas, inclusive pela Associação Brasileira de Criminalística, que varie entre 5\% e $8 \%$ apenas. Este percentual é de $65 \%$ nos Estados Unidos, no Reino Unido é de $90 \%$ e na França é de 80\% (ESTRATÉGIA NACIONAL DE JUSTIÇA E SEGURANÇA PÙBLICA, 2012).

Onde estariam os elementos que provocam tão ampla diferença? Um fator importante a se considerar neste caso no Brasil, entre outros, é que não se prioriza a investigação científica como base sólida para oferecer subsídios concretos para investigações policiais comprometidas com resultados. Entendese como uma necessidade a reestruturação dos órgãos policiais para adequação à atual realidade, bem como investimentos em recursos materiais e humanos, notadamente no plano da investigação criminal científica, e não apenas a modificação ou alteração das leis (BLEICHVEL, 2013). A inovação tecnológica é fundamental para que os instrumentos utilizados por parte dos operadores da segurança pública possam ser eficazes e eficientes. Mecanismos essenciais não têm sido utilizados pelos diversos governos para possibilitar o pensar e o implantar, uma política de segurança pública como instrumento eficiente do Estado (SALES, 2009). 
Tais opções de atuação policial são próprias do processo político e da dinâmica da vida pública e das quais devem resultar diretrizes, princípios, normas legais e parcerias ou convênios que viabilizem a valorização e incremento dos trabalhos da Polícia Científica no Brasil. Lazzarini (1996) defende que a segurança pública é o estado anti-delitual que resulta da observância dos preceitos tutelados pelas leis penais, com ações de polícia repressiva ou preventiva típicas. Fica nítido que a Polícia Científica tem muito a contribuir neste contexto de "estado anti-delitual".

Pode ser entendido que a atual situação da segurança pública no Brasil é um resquício dos aproximadamente 20 anos de ditadura militar em que o país ficou submisso aos interesses de uns poucos e não da totalidade (ESTRATÉGIA NACIONAL DE JUSTIÇA E SEGURANÇA PÚBLICA, 2012). Neste período, a segurança pública era vista como sinônimo de opressão e não de repressão à criminalidade ou combate a impunidade. Este resquício é bem configurado no aspecto em que, na visão da maioria dos policiais no Brasil, entende-se como marginal ou meliante aquele indivíduo pobre e que reside numa favela. Segundo Khong (2001), o conceito de segurança pública moderna traz para a agenda do estado a implementação dos direitos humanos e os problemas de desenvolvimento como pontos prioritários para a segurança.

Segundo Moraes (2008) essa forma de "controle social perverso" pode ser percebida, entre outras maneiras, nos mecanismos que o Estado Brasileiro utiliza para estigmatizar uma categoria social específica: a dos pobres. Como se vê, não pode ser aceita a coexistência de um Estado "para os pobres", onde segurança pública significa mais controle e vigilância e um Estado "para os privilegiados", com controles flexíveis e sem discriminação em face ao maior poder econômico. Neste sentido, Wacquant (2001) afirma que:

Em tais condições, desenvolver o Estado penal para responder às desordens suscitadas pela desregulamentação da economia, pela dessocialização do trabalho assalariado e pela pauperização relativa e absoluta de amplos contingentes do proletariado urbano, aumentando os meios, a amplitude e a intensidade da intervenção do aparelho policial e judiciário, equivale a (r)estabelecer uma verdadeira 'ditadura sobre os pobres'.

Quando se comenta sobre segurança pública no Brasil, entende-se que a filosofia nacional de combate à criminalidade está baseada, na maioria das vezes, em ações imediatistas, sem grande vínculo de planejamento estratégico para o combate contundente ao chamado "crime organizado" (COSTA, 2001). No que pese o efeito psicológico destas ações policiais imediatistas, muitas até com algum caráter burlesco e sensacionalista, em termos de combate para impedir que a criminalidade ocorra e se expanda no meio da sociedade, nada com continuidade e eficiência é estabelecido em termos de políticas públicas (SALES, 2009).

Segundo o Mapa da Violência no Brasil (2014), estudos históricos sobre a violência no Brasil, realizados dentro de uma parceria estabelecida entre a Secretaria-Geral da Presidência da República, da Secretaria Nacional de Juventude (SNJ), da Secretaria de Políticas de Promoção da Igualdade Racial (Seppir), da Organização das Nações Unidas para a Educação, a Ciência e a Cultura (Unesco) no Brasil e da Faculdade Latino Americana de Ciências Sociais 
(FLACSO), a cada hora, cinco pessoas foram mortas por armas de fogo no Brasil em 2012, ou seja, mais de 42,4 mil vidas foram perdidas após disparos de armas de fogo nos 366 dias daquele ano.

Do total de vítimas de arma de fogo, $94 \%$ são do sexo masculino, o levantamento mostra que $94,5 \%$ dessas mortes, mais de 40 mil ao todo, resultaram de homicídios. As demais causas são: acidente (284), suicídio (989) ou indeterminada (1.066) (MAPA DA VIOLÊNCIA NO BRASIL, 2014). Ainda de acordo com o Mapa da Violência no Brasil (2014), entre 1980 e 2012, mais de 880 mil pessoas morreram vítimas de disparo de arma de fogo. Esse número saltou de 8.710, em 1980, para 42.416 em 2012, ou seja, um crescimento de 387\% (MAPA DA VIOLÊNCIA NO BRASIL, 2014). Os governos locais não estão conseguindo combater a criminalidade nas cidades,sendo que a falta de segurança pública contribui significativamente para o aumento destas estatísticas.

De acordo com o Índice de Homicídios na Adolescência (IHA), publicado pelo Observatório de Favelas (2015), "caso a situação não mude, 42 mil adolescentes, de 12 a 18 anos, poderão ser vítimas de homicídio nos municípios brasileiros com mais de 100 mil habitantes entre 2013 e 2019". Ainda de acordo com esta Organização do Terceiro Setor, "o IHA 2012 é o mais alto dos últimos 8 anos, com um aumento de $17 \%$ em relação ao índice medido em 2011". Reforçando as desigualdades regionais, o IHA mostra uma maior incidência de violência letal contra adolescentes na região Nordeste que, segundo os coordenadores do Observatório, estaria associado aos crescimentos econômico e demográfico desordenados nessa região. Por outro lado, "foi verificada uma redução da mortalidade de adolescentes na região Sul" (OBSERVATÒRIO DAS FAVELAS, 2015).

Isto aponta que o Brasil não está conseguindo combater de forma efetiva a questão da violência. Cotrim (1989) defende que:

\footnotetext{
Infelizmente, o governo tem usado ferramentas erradas e conceitos errados na hora de entender o que é causa e o que é conseqüência. A violência que mata e que destrói está muito mais para sintoma social do que doença social. Aliás, são várias as doenças sociais que produzem violência como um tipo de sintoma. Portanto, não adianta super-armar a segurança pública, lhes entregando armas de guerra para repressão policial se a "doença" causadora não for identificada e combatida.
}

Neste contexto, os governos precisariam descobrir as razões do aumento desses índices nos últimos anos, para assim estabelecer políticas públicas eficazes nesta área, favorecendo, ao mesmo tempo, um desenvolvimento estruturado e sustentável. Este é um assunto que passou a preocupar os cidadãos, diante do aumento das taxas de roubos e homicídios, da baixa resolução dos crimes e do real aumento da sensação de insegurança. A falta de transparência na divulgação dos dados seria outro fator que dificulta a criação de um plano nacional de segurança consistente e de qualquer outro planejamento estratégico nesta área. 


\section{GASTOS COM SEGURANÇA PÚBLICA}

Processos rápidos de industrialização e urbanização provocam fortes movimentos migratórios, concentrando amplas massas isoladas nas periferias dos grandes centros urbanos. As múltiplas carências das populações de baixa renda precariamente assistidas nestas periferias, tornam seus integrantes, especialmente os mais jovens, altamente suscetíveis de escolhas ilegais como forma de sobrevivência ou de ascensão social (LEAL, 2003). Desta forma, o combate ao crime e à violência deveria se iniciar com políticas públicas que possibilitem prevenir a não iniciação de crianças e adolescentes ao uso de drogas, ao contato com armas, entre outros fatores (PROCOPIO, 1999). E isso somente será bem feito se existirem dados, informações que auxiliem a detectar onde está a raiz do problema e indicar as melhores formas de atuação no combate e prevenção do crime e violência. As estratégias reativas da polícia e os métodos obsoletos de investigação não estão conseguindo conter significativamente o grande volume de crimes. A ineficiência da ação policial na contenção dos crimes decorre dessas deficiências e do emprego de estratégias policiais meramente reativas e repressivas (BEATO FILHO, 1999).

Segundo Carvalho (2006), à medida que o crime vai aumentando numa determinada região, a atratividade deste local diminui. $O$ turismo de uma região também é recuperado quando se combate a criminalidade. Em cidades alvos de ataques violentos cai a capacidade de atrair turistas (CARVALHO, 2006). Um exemplo apontado pelo autor é o México, onde por conta do alto índice de pessoas envolvidas com o narcotráfico, transmite insegurança para várias empresas que tem por objetivo instalar fábricas no país, que receosas de colocar seus funcionários num local considerado arriscado, escolhem outros locais para investir. Esse processo maléfico gera um aumento de desemprego na região afetada pelo crime e se não são tomadas medidas efetivas para aumentar a segurança pública, gera grandes problemas sociais e econômicos em termos de sucateamento do desenvolvimento local (CARVALHO, 2006).

Luhnow (2010), por sua vez, aponta que devido à ascensão do narcotráfico calcula-se que deixaram de ser investidos US\$ 4 bilhões no México no ano de 2010. Isto também ocorre no Brasil, mostrando que, além de ser um problema social, a criminalidade é, também, um problema econômico e que deve ser tratado com altíssima prioridade. Segundo Pereira et al. (2006), no Brasil, custo estimado da violência no Brasil é de aproximadamente trezentos milhões de reais por dia, obviamente uma cifra muito elevada para resultados tão pequenos. É fácil verificar que com tal custo pago pela sociedade não é possível investir corretamente em ações de desenvolvimento econômico. Em suma, insegurança emperra a economia como um todo e provoca atrasos em áreas vitais para melhoria do bem-estar social.

Conforme Belchior (2007) ainda devem ser relacionados os problemas psicológicos que acometem os parentes das vítimas de mortes por violência, tais como depressão e estresse vinculados às lembranças dos fatos passados associados ao crime, o que gera reflexos financeiros ao nível de programas de saúde e educação.

Se existem os custos decorrentes da criminalidade, também ocorrem (2007), esses valores poderiam ser reduzidos caso houvesse uma maior 
preocupação com a prevenção da criminalidade. Analisando os dados expostos por Lima et al. (2010), verifica-se que os percentuais gastos com informação e inteligência policial são insignificantes comparativamente às demais funções da Segurança Pública, representando apenas $0,84 \%$ do total de gastos no ano de 2009 , sendo que a prevenção e combate a criminalidade muito depende desta atividade de inteligência e expertise e não somente do policiamento. A figura 01 mostra os gastos com segurança pública realizados pelo Estado de São Paulo, o mais rico do Brasil, mostrando as diferenças entre os gastos com informação e inteligência e os aplicadas no mero policiamento padrão, ou seja, sem visão de inovação tecnológica.

Figura 01 - Despesas com segurança pública estabelecidas pelo Estado de São Paulo Anos de 2004 a 2008

\section{Despesas com segurança pública}

\begin{tabular}{|c|c|c|c|c|c|}
\hline \multirow{7}{*}{$\begin{array}{r}100,00 \% \\
90,00 \% \\
80,00 \% \\
70,00 \% \\
60,00 \% \\
50,00 \% \\
40,00 \% \\
20,00 \% \\
10,00 \% \\
0,00 \%\end{array}$} & \multirow{6}{*}{\multicolumn{2}{|c|}{\begin{tabular}{|l|l|l|} 
& \\
& \\
& \\
& \\
& \\
& \\
& \\
& \\
& \\
& \\
& \\
& \\
\end{tabular}}} & \multirow{6}{*}{ 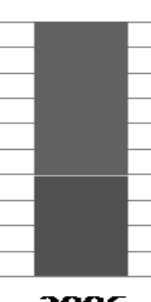 } & \multirow{7}{*}{2007} & \multirow{7}{*}{$\mathbf{2 0 0 8}$} \\
\hline & & & & & \\
\hline & & & & & \\
\hline & & & & & \\
\hline & & & & & \\
\hline & & & & & \\
\hline & 2004 & & & & \\
\hline Policiamento & $57,81 \%$ & $58,06 \%$ & $60,14 \%$ & $63,33 \%$ & $84,68 \%$ \\
\hline Informação e Inteligência & $0,04 \%$ & $0,07 \%$ & $0,04 \%$ & $0,07 \%$ & $1,44 \%$ \\
\hline Defesa Civil & $0,26 \%$ & $0,26 \%$ & $0,21 \%$ & $0,24 \%$ & $0,24 \%$ \\
\hline Demais Subfunçöes & $41,89 \%$ & $41,61 \%$ & $39,60 \%$ & $36,36 \%$ & $13,65 \%$ \\
\hline
\end{tabular}

Fonte: SBAC Advogados (2010)

POLÍCIA COMUNITÁRIA: INSTRUMENTO DE DESENVOLVIMENTO LOCAL

O desafio de todos os governos está em associar políticas permanentes de Estado na área de segurança pública com aquelas políticas específicas que estimulam um ambiente favorável à construção de um desenvolvimento econômico sustentável. Pode-se elencar, por exemplo, o apoio ao empreendedorismo e associativismo; o acesso à tecnologia e à inovação; à formação e educação com qualidade em larga escala, atingindo todas as classes sociais. Também é fundamental tornar as ações e esforços rumo a este desenvolvimento econômico sustentável em ações de longo prazo que respeitem as especificidades locais.

Assim são abertos e estimulados novos empreendimentos, tendo tal população ocupação certa e rentável, não permanecendo à mercê dos abusos e imposições da marginalidade para obter serviços públicos e padrões dignos para uma boa qualidade de vida. Diz o senso comum no Brasil que onde o Governo está ausente o banditismo domina e ocupa o espaço, expulsando o cidadão de bem. Isto, certamente, emperra o processo de desenvolvimento. De acordo com 
Beato Filho (1999), essa visão deturpada de valores pode acabar se as instituições policiais forem adequadamente empregadas, se utilizando para tal de expertise e inteligência policial (atividade que objetiva a obtenção, análise e produção de conhecimentos de interesse da segurança pública sobre fatos e situações de imediata ou potencial influência da criminalidade, atuação de organizações criminosas, controle de delitos sociais, assessorando as ações de polícia judiciária e ostensiva por intermédio da análise, compartilhamento e difusão de informações) para monitorar e eliminar núcleos criminosos que usualmente procuram as comunidades mais carentes para prosperar e assim subjugar o restante da sociedade organizada.

O Estado e a sociedade local devem identificar conjuntamente as oportunidades econômicas existentes e planejar sua atuação no sentido de fortalecer estas escalas econômicas positivas, permitindo assim criar condições para um ambiente favorável aos micro e pequenos empreendimentos, que com o desenvolvimento sustentável, num ambiente de segurança pública permanente, podem "desenvolver cadeias produtivas com as quais os empreendimentos econômicos solidários possam negociar e disputar em melhores condições frente às grandes empresas privadas" (SINGER, 2004).

Com base nos pressupostos anteriores e em experiências internacionais, o sentimento de segurança pública junto às comunidades em geral poderia ser fortalecido pela instauração do mecanismo denominado como Polícia Comunitária e Cidadã. Esta forma de policiamento é muito empregada em países desenvolvidos (tais como EUA, Japão, Coréia do Sul, Grã-Bretanha, Alemanha, Canadá e França), onde o policial é visto como membro efetivo da comunidade, participando de suas peculiaridades e, em muitos casos, residindo na própria comunidade ou numa área próxima (MARCINEIRO, 2009). Neste sistema, o policial colabora para o estímulo e a difusão do espírito associativo, e para a utilização de decisões e soluções coletivas para os graves problemas que podem ser vivenciados por aquela comunidade. Conforme Reale (2005), Polícia Cidadã é uma polícia forte, honrada e justa, capaz de realizar qualquer ato legal possível para defender os direitos ultrajados do cidadão cumpridor dos seus deveres e obrigações. É uma polícia sempre em defesa do cidadão e com o seu labor direcionado verdadeiramente a serviço da comunidade. Ainda, de acordo com Marcineiro (2009), a polícia cidadã e comunitária vivencia tudo isso, pois as suas decisões e atuação são embasadas na parceria com o cidadão, gerando confiança e respeito mútuos em benefício da própria comunidade.

Segundo Oliveira (2006), a polícia comunitária:

Assenta-se na descentralização organizacional e na reorientação das patrulhas, com vista a facilitar a dupla comunicação, entre a polícia e o público; pressupõe uma orientação virada para uma ação policial, concentrada na resolução dos problemas; obriga os policiais (a partir do momento que eles definem os problemas locais e as suas prioridades) a estar atentos às solicitações dos cidadãos; significa ajudar os bairros a resolver por eles próprios os problemas de delinqüência, devido às organizações de proximidade e aos programas de prevenção do crime. demonstrar que o Estado realmente está próximo e favorece o cidadão e que 
seus tributos estão sendo bem empregados. Isso passa pela aceleração tecnológica dos mecanismos e instrumentos policiais (qualificada como uma polícia inovadora e atualizada), desde estrutura física melhorada até a expertise a ser dominada pelos policiais, definindo assim um ciclo contínuo de atualização e inovação que transmita a imagem de competência e eficiência permanentes aos olhos da população.

Entende-se que os conceitos de segurança pública e segurança humana se reforçam mutuamente. "Segurança humana não é uma preocupação com armas, mas com a vida humana e a dignidade" (UNITED NATIONS DEVELOPMENT PROGRAM, 1994).

\section{EXPERIÊNCIAS UNINDO SEGURANÇA E DESENVOLVIMENTO}

Nesta subseção serão apresentados alguns casos de sucesso de ações de segurança pública com impactos no desenvolvimento local. Segundo Robert Putnam (1993), a forma de desenvolvimento do capital social de um país é mais válida se derivada da intensa e contínua relação com uma cultura cívica apropriada.

\section{O CASO DE BOGOTÁ NA COLÔMBIA}

O caso da cidade de Bogotá é bem elucidativo em termos de exemplificação do que ocorre quando o Estado faz uma intervenção adequada e eficiente no fator segurança pública, com políticas que levam a população a sentir um novo horizonte de possibilidades. Bogotá detinha a infeliz fama de ser uma das cidades mais violentas do mundo (CARVALHO, 2001). Assim, conforme Carvalho (2001), a prefeitura de Bogotá planejou programas junto com os órgãos de segurança e com a sociedade em geral. O resultado disto, ainda conforme Carvalho (2001), foi a diminuição da violência atacando-a de uma forma indireta e com interação com a comunidade. Medidas como fechamento de casas noturnas na madrugada, controle de condutores embriagados, programa de desarmamento e a construção de parques para que ocorresse o contato entre os munícipesforam de grande valia (CARVALHO, 2001).

Também, segundo Carvalho (2201), foi realizado de maneira paralela um completo levantamento e tratamento de dados, o chamado Sistema Unificado de Informação e Violência e Delinquência, do qual participaram a Prefeitura de Bogotá, o órgão de Medicina Legal e a Polícia Metropolitana. Desta forma a população começou a perceber que segurança era associada à polícia e não aos narcotraficantes que dominavam a cidade, sendo que após a eliminação destes problemas de criminalidade, foi incentivado o empreendedorismo local (setores de turismo e serviços) por toda a cidade (CARVALHO, 2001).

\section{O EXEMPLO DO SISTEMA KOBAN (JAPÃO)}

Uma experiência internacional que obteve grande sucesso é o Sistema Koban. Implementado no Japão. Conforme JPDIEA (2010), oskobans foram criados para promover vigilância ininterrupta e constante de policiais em uma determinada região, baseado num posto policial de serviço, atuando côo uma 
força integrada com a comunidade e agindo principalmente em ações preventivas.

Segundo Brandão et al. (2009), koban significa basicamente vigilância, tendo sido criado a mais de 100 (cem) anos, constituídos de postos policiais distribuídos em todo o país com o objetivo de prevenir crimes e atender acidentes (Figura 2). A visibilidade e acessibilidade dos policiais é um aspecto importante, fazendo com que a população sinta segurança. Ainda conforme os autores, a polícia mostra à sociedade que existe uma lei e que segurança pública é um problema de todos. O patrulhamento é feito a pé, em bicicletas, veículos motorizados e embarcações (BRANDÃO et al., 2009).

Conforme JPDIEA (2010), os policiais lotados num koban ajudam a controlar o trânsito nas ruas e horas de maior movimento, bem como realizam visitas periódicas ao comércio e até as casas da sua área de patrulhamento, montando assim um mapeamento da vizinhança em que atuam. Assim, eles identificam quem mora e quem trabalha na sua área de atuação e jurisdição, sabendo desta forma onde estão os possíveis focos de problemas (JPDIEA, 2010).

Figura 02 - Prédio de um koban padrão em um bairro de Tóquio, Japão

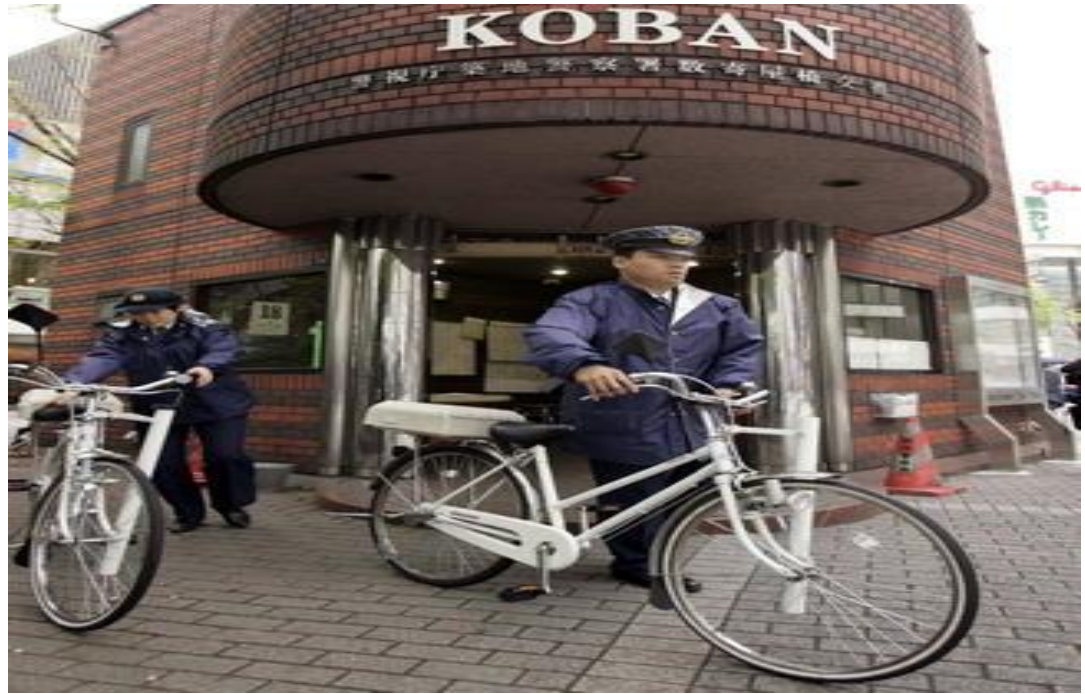

Fonte: Polícia Comunitária (2015)

\section{A EXPERIÊNCIA DA UPP NO RIO DE JANEIRO}

No Brasil pode ser citada como uma experiência positiva as Unidades de Polícia Pacificadora estabelecida em algumas favelas (comunidades carentes) no Estado do Rio de Janeiro. Unidade de Polícia Pacificadora (UPP) é um dos mais importantes programas de Segurança Pública realizado no Brasil nas últimas décadas. Implantado pela Secretaria de Segurança do Rio de Janeiro, no fim de 2008, foi planejado e coordenado pela Subsecretaria Estadual de Planejamento e Integração Operacional.

A UPP foi baseada nos princípios da polícia de proximidade, que tem por estratégia a parceria entre a população e a polícia e instituições outras de segurança pública (CARVALHO, 2013). Ainda conforme Carvalho (2013) a 
retomada agressiva por forças de segurança de áreas marginalizadas estava associada ao conceito de Unidade de Polícia Pacificadora Social (UPP SOCIAL). Esta UPP com caráter social, segundo Carvalho (2013), deveria consolidar o controle territorial mediante policiamento ostensivo e expulsão de grupos marginais armados de uma dada região, bem como auxiliar no desenvolvimento social e econômico desta região, sendo que a Prefeitura da cidade do Rio de Janeiro e o Governo de Estado deveriam promover urbanização e oferta de serviços públicos, tais como fornecimento de energia elétrica e água potável.

Os efeitos das UPP já estão sendo sentidos em vários níveis, como por exemplo, a valorização dos imóveis próximos às regiões onde há uma UPP instalada. Conforme Silva e Carvalho (2013), o policiamento também contribuiu para o aumento da liquidez, ficou mais fácil vender imóveis nas regiões pacificadas. Ainda segundo Silva e Carvalho (2013), a partir da pacificação da comunidade, a Secretaria de Estado de Turismo, Esportes e Lazer começa agora alguns projetos para a preparação dos moradores e dos novos comerciantes neste projeto turístico de inclusão social.

Assim, com a UPP ocorre uma retomada do crescimento econômico garantida pelas ocupações policiais, favorecendo um modelo de comunidade voltada para o lucro e para o desenvolvimento econômico e social. Os reflexos práticos com o emprego correto da UPP, por exemplo, podem ser visualizados nas figuras 03 e 04, sendo estes indicadores sociais das situações vivenciadas por aquelas comunidades que foram beneficiadas pela implantação de políticas públicas voltadas para polícia comunitária e pacificação de espaços urbanos.

Figura 03 - Incidência de tiroteio antes e após a ocupação nas favelas beneficiadas com UPP - Ano referência 2013

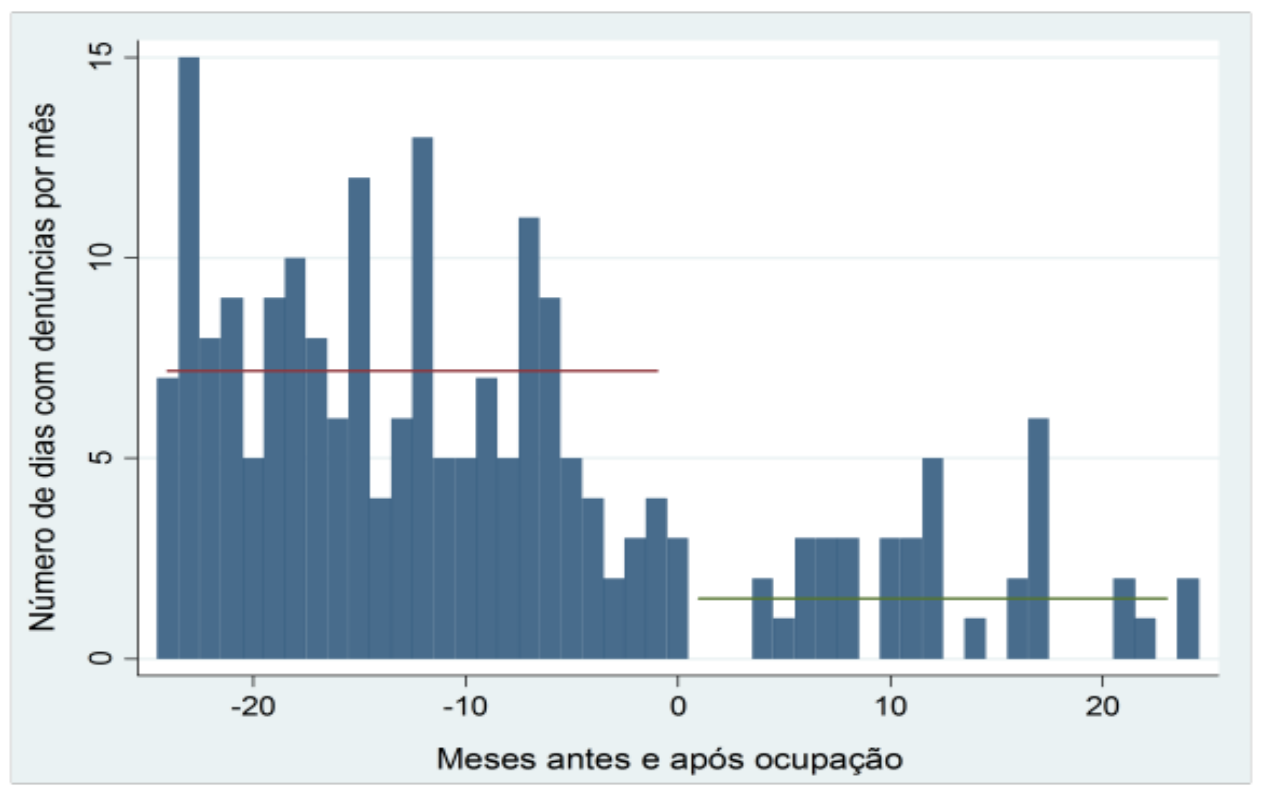

Fonte: O Agente Principal - Serviços Públicos em Foco (2014)

O gráfico da figura 3 é baseado no número de denúncias sobre confrontos entre facções de drogas feitas ao Disque-Denúncia, nas 34 UPPs (AGENTE PRINCIPAL, 2014). "A média de denúncias nos 24 meses que antecederam a 
ocupação policial era de sete ao mês, tendo o mesmo número passado para uma denúncia em média após a ocupação" (AGENTE PRINCIPAL, 2014). Portanto, mesmo que a ocupação policial não tenha acabado totalmente com esse tipo de confronto nessas comunidades, ela conseguiu reduzir de maneira significativa a sua frequência (AGENTE PRINCIPAL, 2014).

Já o gráfico da figura 4 mostra a diminuição clara do número de mortes na cidade do Rio de Janeiro, no período de 2006 e 2013. A taxa de letalidade violenta do segundo semestre de 2013 (13 mortes por 100 mil habitantes) é menos da metade da taxa do segundo semestre de 2006 (27 mortes por 100 mil habitantes) (AGENTE PRINCIPAL, 2014).

Figura 04 - Taxa de letalidade violenta no município do Rio de Janeiro (número de mortes por 100 mil habitantes) e população residente em favelas pacificadas - Referência 2013

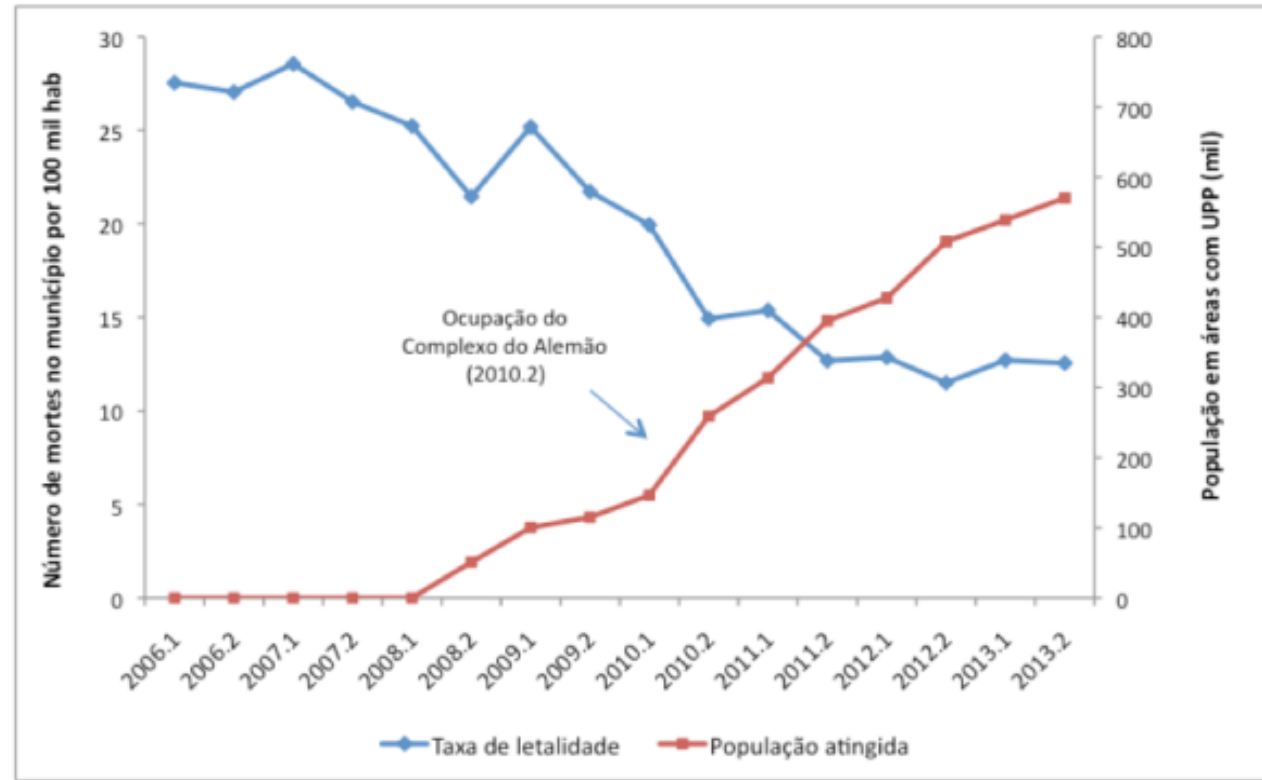

Fonte: O Agente Principal - Serviços Públicos em Foco (2014)

Nos gráficos expostos nas figuras apresentadas fica clara a eficiência do Programa UPP como um divisor de águas nas questões de tiroteios e letalidade nas áreas marginalizadas ocupadas. De certo modo, isto valida uma possível aplicação de tal programa como política pública em nível nacional, obviamente com o devido aprofundamento nas concepções e rotinas de operacionalização necessárias para aplicação contínua e por maior prazo, causando assim o efeito de segurança pública desejado. Para Jacobs (2001) nada melhor para a sensação coletiva de segurança que a confiança nas ruas formadas a partir de inúmeros contatos coletivos nas calçadas, parques, ruas, equipamentos públicos e privados envoltos pela vizinhança.

\section{ASPECTOS METODOLÓGICOS}

A presente pesquisa, de natureza aplicada, com abordagem qualitativa do problema, e descritiva no que se refere ao seu objetivo, foi desenvolvida por meio de documentação indireta, no caso por uma pesquisa bibliográfica. Em 
termos de natureza das obras selecionadas, buscou-se informações, principalmente, em livros e foram consultados também sítios eletrônicos de entidades que disponibilizam dados sobre o assunto da segurança pública no Brasil.

A coleta e análise dos dados foi guiada pelo interesse em relacionar características da segurança pública com as do desenvolvimento local.

\section{DISCUSSÃO DOS RESULTADOS}

Obviamente, que a sensação de segurança faz com que o cidadão vislumbre o futuro com outros olhos e que assim, com a paz e serenidade estabelecida numa comunidade, as ações governamentais de inserção social e de cidadania sejam realizadas com maior freqüência e com espectro de alcance cada vez maior. Isto permite que as pessoas acreditem que uma vida melhor não somente é possível, mas que pode ser exigida e democraticamente conquistada. Deste modo fica fortalecido o conceito de que segurança eficiente gera cidadão mais consciente dos seus direitos e cumpridor dos respectivos deveres, tornando a sociedade mais sadia e focada na prosperidade e crescimento sustentáveis.

As experiências exitosas analisadas sobre Polícia Comunitária confirmam que o foco na proteção dos direitos a uma vida digna e na integridade física e material são as bases da segurança, um bem público e que todas as pessoas devem ter acesso, e como tal, sua provisão é de responsabilidade do Estado. Para que o desenvolvimento econômico e social ocorra numa dada comunidade devem ocorrer esforços para reduzir a criminalidade e a violência, incluindo um acordo nacional de segurança, como política de Estado, bem como potencializar a participação ativa da sociedade, especialmente as comunidades locais, na construção da segurança cidadã (AGENTE PRINCIPAL, 2014; BRANDÃO et al., 2009; CARVALHO, 2001; JPDIEA, 2010; SILVA; CARVALHO, 2013;).

Mas não se trata somente de instaurar mecanismos de consulta das expectativas da sociedade, mas é fundamental que as instituições policiais se abram às idéias, opiniões e propostas da sociedade civil organizada especializada. Para isso devem ser tomadas algumas medidas emergenciais: construir canais de diálogo e cooperação entre os membros das forças policiais e os membros da sociedade civil e os pesquisadores da área; capacitar policiais que poderão estar em posições de comando daqui a alguns anos e aperfeiçoar a sua participação em discussões sobre reforma da polícia, e desenvolver os mecanismos necessários para que os atores desta questão possam exercer influência nas agendas nacionais e regionais de segurança públicaA resposta à criminalidade passa por um processo coordenado pelo poder público de interação com a comunidade, assim como aconteceu na Colômbia e no Brasil (CARVALHO, 2001).

A mudança de paradigma a ser proposta às polícias brasileiras é de transitarem para o policiamento democrático, dependendo muito de políticas de Estado essencialmente transformadoras e inovadoras nesta área tão sensível que é a segurança pública. $O$ que efetivamente medirá o grau de eficiência desta política pública é o envolvimento popular nesta questão. Reforçando o entendimento de Cotrim (1989), a segurança cidadã se refere a uma ordem 
cidadã democrática que elimina as ameaças de violência na população e permite a convivência segura e pacífica.

Fica claro no estudo apresentado, principalmente no caso das experiências de Polícia Comunitária, que o processo coletivo de construção fez com que os diversos atores de uma política de segurança cidadã (gestão pública, comunidade, terceiro setor e setor privado) ecoassem suas vozes, trazendo propostas inovadoras, ousadas e possivelmente eficazes (CARVALHO, 2001), mas também esclarecendo seus limites e possibilidades para aplicação de políticas públicas que levem ao desenvolvimento local pleno a partir de uma base sólida em termos da reformulação do concepção de segurança pública no Brasil

Fica assim mostrado que o combate à criminalidade necessita que uma nova cultura, um novo aprendizado seja formado inicialmente com repressão dura da polícia contra os marginais e, posteriormente, com investimentos maciços nas condições de segurança pública no Brasil, como uma política de Estado permanente e não uma mera e passageira política governamental oportunista, pois desta maneira será possível promover desenvolvimento local, o que muito irá contribuir para diminuir os bolsões de miséria que ocorrem no país.

A paz, a segurança, tem influência direta no desempenho das atividades econômicas da localidade. Um exemplo simples é o impacto na valorização dos imóveis em comunidades assistidas pelas polícias comunitárias, pacificadoras (SILVA; CARVALHO, 2013). Evidentemente, a insegurança tem um custo alto também para os governos (PEREIRA, 2006). Recursos para cobrir estes custos poderiam estar sendo aplicados em outras áreas fundamentais de responsabilidade do Estado, como saúde, educação, por exemplo. Do ponto de vista da iniciativa privada, a insegurança local impede o território, o espaço local, de se inserir no espaço global (SANTOS, 2012; SASSE, 2010) por falta de competividade. Espaços locais problemáticos acabam sendo rejeitados no mundo globalizado.

\section{CONCLUSÃO}

O objetivo deste estudo era o de relacionar segurança pública com aspectos do desenvolvimento local. O estudo mostrou que segurança pública é preocupação das sociedades, de países de todos os níveis de desenvolvimento socioeconômico. Evidentemente, em países como México, Colômbia e Brasil, citados no estudo, que buscam um patamar de desenvolvimento avançado mas que convivem com índices de violência incompatíveis com esta pretensão, o desafio é muito maior. Há um círculo vicioso envolvendo (in)segurança pública e desenvolvimento socioeconômico. O custo da (in)segurança pública, aos cofres públicos e à sociedade civil de um modo geral, é tão significativo que acaba inibindo o investimento dos governos e dos cidadãos em infraestrutura, em educação e em saúde e em produção (desenvolvimento socioeconômico).

Como foi visto também, a insegurança pública inibe investimentos externos uma vez que o mundo globalizado pede espaços locais em condições de fazer parte deste movimento. Os territórios precisam apresentar atributos básicos para poderem se inserir na rede global de trocas comerciais e de mobilidade de de primeira linha. Um resultado importante do estudo é o papel das polícias 
neste contexto. Considerando-se que um dos maiores problemas enfrentados pelas instituições policiais atualmente, é a sua crise de legitimidade com respeito à sociedade. No entanto, indivíduos e organizações da sociedade civil, juntando forças para reformar as instituições policiais de uma dada região ou comunidade, já conseguiram estabelecer ações e propostas de mudanças que causam impacto direto no desenvolvimento econômico local.

Em termos de contribuição, este estudo contribui com resultados significativos sobre a associação de temas pouco discutidas na literatura (segurança pública - desenvolvimento econômico), e oferece um percurso para estudos mais extensos, mais profundos e mais conclusivos nesta área, tão esperados pela sociedade brasileira. 


\title{
Public safety and local development: Experiences of Brazil, Colombia and Japan
}

\begin{abstract}
A society to thrive need to feel safe in the whole concept of the term. Indeed, this understanding involves the preservation of safety and security. This article will relate to public safety aspects of local development. The research aims to discuss a new public safety vision, a certain degree of influence, can contribute to the economic development of a city, a region or even a country. In terms of methodology, there search uses the literature research technique, a qualitative analysis of the problem. The main results the research points to the need to design appropriate public safety to a democratic state, and including economic, social and cultural security, using the least possible force and maximum expansion of opportunities and social rights.
\end{abstract}

Keywords: Public Security. Local Development. Community Police. 


\section{REFERÊNCIAS}

BEATO, Claudio C.; CLÁUDIO, C. Ação e estratégia das organizações policiais. In: Segundo seminário Polícia e Sociedade Democrática, Rio de Janeiro, v. 11, 1999. Disponível em: <http://docplayer.com.br/2862513-Acao-e-estrategia-dasorganizacoes-policiais.html>. Acesso em: 20 jan. 2016

BELCHIOR, Fátima. Os custos da violência no Brasil. Rio de Janeiro:IPEA, 2007. Disponível em: $<$ http://desafios2.ipea.gov.br/003/00301009.jsp?ttCD CHAVE=2518>. Acesso em: 05 jun. 2015.

BLEICHVEL, Marise A.; KRIEGER, Jorge R.A eficácia da investigação criminal pela polícia judiciária e pelo ministério público. Revista Eletrônica de Iniciação Científica. Itajaí, Centro de Ciências Sociais e Jurídicas da UNIVALI. v. 4, n.3, p. 824-843, 3o Trimestre de 2013. Disponível em:<www.univali.br/ricc - ISSN 22365044>. Acesso em 18 jun. 2015.

BRANDÃO, Ailton A.et al. Curso Internacional de Multiplicador de Polícia Comunitária: Sistema Koban. Programa Nacional de Segurança Pública com Cidadania - Pronasci. 3. ed. Brasília, DF: Ministério da Justiça/SENASP/PMESP, 2009.

BRASIL. Constituição da República Federativa do Brasil. 42a edição, ampliada e atualizada até a Emenda Constitucional no. 57, de 18/12/2008. São Paulo: Saraiva, 2009.

CARVALHO, Giane C. A. Juventude e Políticas Públicas: dos impasses às necessidades básicas. In: MATOS, Kelma Socorro Lopes; ADAD, Shara Jane Holanda Costa (Org.). Outras Imagens. Fortaleza, UFC edições, 2006.

CARVALHO, Monique B. A política de pacificação de favelas e as contradições para a produção de uma cidade segura. O Social em Questão, Ano XVI, no 29, 2013.

CARVALHO, Nelson; CASTANHEIRA, Leila. Relatório Bogotá - Colômbia. Rio de Janeiro: Rio Estudos, 2001.

COSTA, N. R.. Ofício de Polícia, Violência Policial e Segurança Pública em Mato Grosso. In: Seminário Nacional: O Papel das Universidades na Construção de Novos Modelos de Polícia, 2001, Porto Alegre-RS. Caderno de Resumo de Trabalhos. Porto Alegre - RS, 2001. 
COTRIM, Gilberto V. Acorda Brasil: o que você deve saber sobre a Constituição. São Paulo : Saraiva, p.105, 1989.

ESTRATÉGIA NACIONAL DE JUSTIÇA E SEGURANÇA PÚBLICA. Relatório Nacional da Execução da Meta 2 : um diagnóstico da investigação de homicídios no país. Brasília: Conselho Nacional do Ministério Público, 2012. Disponível em: <http://www.cnmp.gov.br/portal 2015/images/stories/Destaques/Publicacoes/R elatorio Enasp - FINAL - web.pdf>. Acesso em 10 jun. 2015.

JACOBS, Jane. Morte e Vida de Grandes Cidades. São Paulo: Martins Fontes, p.60-69,2001.

JPEDIA. Polícia Metropolitana de Tokyio: Keishicho. 02/11/2010. Disponível em: $<$ http://ipedia.jp/tikiindex.php?page $=$ Pol\%C3\%ADcia+Metropolitana+de+Tokyo >. Acessoem $17 \mathrm{jul}$. 2015.

KHONG, Y. F. Human Security: A Shotgun Approach to Alleviating Human Misery?Global Governance. p.234, 2001.

LAZZARINII, Álvaro. Polícia e Direito: Abuso de poder x poder de polícia. Revista Brasileira de Ciências Criminais, ano 4, número 14 (abr-jun/96), São Paulo: Editora Revista dos Tribunais, p. 53, 1996.

LEAL, César B.; PIEDADE JÚNIOR, Heitor (organizadores). A violência multifacetada: estudos sobre a violência e a segurança pública. Belo Horizonte: Del Rey, 2003.

LIMA, Renato S. de et al. Anuário do Fórum Brasileiro de Segurança Pública. São Paulo, 2010. Disponível em:

<http://www.forumseguranca.org.br/storage/download/anuario 2010.pdf>. Acesso em: 28 jul. 2015

LUHNOW, David; HAGERTY, James R. Violência leva empresas a rever planos para o México. Valor Econômico. São Paulo, caderno B, p.11, 17/12/2010.

MAPA DA VIOLÊNCIA 2014. Homicídios e Juventude no Brasil - Atualização 15 a 29 anos. Disponível em: <www.juventude.gov.br/juventudeviva>. Acesso em: 30 jun. 2015.

MARCINEIRO, N. Polícia comunitária: construindo segurança nas comunidades. 
Florianópolis: Editora Insular. 2009.

MELLO, Marco A. da S.; CUNHA, Neiva V.da.A UPP e o processo de urbanização na favela Santa Marta: notas de campo. In: MELLO, Marco Antonio da Silva [et al] (org.) Favelas Cariocas: ontem e hoje; Rio de Janeiro: Garamond, 2012.

MORAES, P. R. B. ; SALLAS, A. L. F. ; BEGA, M. T. S. ; VILLA, R. A. D. . Os jovens de curitiba: esperanças e desencantos (juventude, violência e cidadania). Curitiba: Editora da Universidade Federal do Paraná, 2008.

OBSERVATÓRIO DE FAVELAS. Índice de Homicídios Na Adolescência. Disponível em: <http://observatoriodefavelas.org.br/noticias-analises/indicede-homicidios-na- dolescencia-e-o-mais-alto-em-8-anos>. Acesso em: 01 jun. 2015.

O AGENTE PRINCIPAL. Joana Monteiro. Os Locais Priorizados Pela Política de Pacificação. Disponível em: <https://oagenteprincipal.wordpress.com/tag/upp/>. Acesso em: 05 jun. 2015

OLIVEIRA, José F. de. As políticas de segurança e os modelos de policiamento - A emergência do policiamento de proximidade, Ed. Almedida, Coimbra, p.115, 2006.

PEREIRA, Ana C. do R.; et al.Polisafe do Brasil Limitada. p.19, 2006.

Disponível em:

< http://www.pucpr.br/cursos/graduacao/ccsa/administracao/projeto empresari al/pdfs/projeto polisafe.pd f.> Acesso em: 25 jul. 2015.

PINHEIRO, Paulo S. 1998. Polícia e Consolidação Democrática: o caso brasileiro. In:São Paulo sem Medo : um Diagnóstico da Violência Urbana.ED. Garamond. S. Paulo.

PROCOPIO, Argemiro. O Brasil no Mundo das Drogas. Petrópolis: EditoraVozes, 1999.

PUTNAM, R. The Prosperous Community.Social Capital and Economic

Growth.The American Prospect, Spring, 1993. 
REALE, Miguel. O Estado Democrático de Direito e o conflito das ideologias. 3a Ed.. São Paulo: Saraiva, 2005.

ROCHA, Arimá. Violência:Direitos humanos e segurança. Jornal Diário do Nordeste. Ceará, 22 maio. p.25. 2005. Caderno de Cultura.

RODRIGUES, Rute I. et al.Custo da Violência para o Sistema Público de Saúde no Brasil. Brasília : IPEA, 2007

SALES, Lília M. de M.;NUNES, A.;FERREIRA, P. R. L.. Segurança Pública, Mediação de Conflitos e Polícia Comunitária: uma Interface. Novos Estudos Jurídicos (Online), v. 14, 2009.

SANTOS, Milton. A natureza do espaço. 4으. Ed. São Paulo : Edusp, p. 337, 2012

SASSEN, S. Sociologia da Globalização. Porto Alegre: Artmed, p.20, 2010.

SBAC AVOGADOS. Despesas com segurança pública estabelecidas pelo Estado de São Paulo. Disponível em:<http://oprocessopenal.blogspot.com.br/2010/05/estatisticas-criminaisinvestimentos-em.html>. Acesso em: 10 jun. de 2015.

SILVA, F. D.; CARVALHO, F. C. O Programa UPP Na Comunidade Santa Marta, Rio de Janeiro e a Dimensão da Inclusão SocioEspacial. In: XV Enanpur - Desenvolvimento, Planejamento e Governança, 2013, Recife. XV Enanpur, p.7 - 9, 2013. Disponível em: <>.Acesso em: 22 jun. 201 http://unuhospedagem.com.br/revista/rbeur/index.php/anais/article/viewFil e/4254/41245.

SINGER, P. Épossível levar o desenvolvimento a comunidades pobres? Brasília: Secretaria Nacional de Economia Solidária/ Ministério do Trabalho e Emprego, 2004.

UNITED NATIONS DEVELOPMENT PROGRAM (1994).Human Development Report 2004.Disponível em: <http://hdr.undp.org/en/media/hdr04 complete.pdf>. Acesso em: 25 jun. 2015.

WACQUANT, L.As prisões da miséria. Tradução de André Telles. Rio de Janeiro: Jorge Zahar Ed., p.10, 2001. 
Recebido: 03 fev. 2016.

Aprovado: 08 mar. 2016.

DOI: $10.3895 /$ rbpd.v5n3.3790

Como citar: NASCIMENTO, D. E.; TEIXEIRA, M. A. N. Segurança pública e desenvolvimento local:

Experiências do Brasil, Colômbia e Japão. R. bras. Planej. Desenv., Curitiba, v. 5, n. 3, p. 365-385, set./dez.

2016. Disponível em: <https://periodicos.utfpr.edu.br/rbpd>. Acesso em: XXX.

Correspondência:

Decio Estevão do Nascimento

Rua Av. Sete de Setembro, 3165, Centro, Curitiba, PR.

Direito autoral: Este artigo está licenciado sob os termos da Licença CreativeCommons-Atribuição 4.0

Internacional. 